\title{
Does comparative-effectiveness research threaten personalized medicine?
}

\section{Citation}

Garber, Alan M., and Sean R. Tunis. 2009. Does comparative-effectiveness research threaten personalized medicine? New England Journal of Medicine 360, 19:1925-1927.

\section{Published Version}

doi:10.1056/NEJMp0901355;http://www.nejm.org/doi/full/10.1056/NEJMp0901355

\section{Permanent link}

http://nrs.harvard.edu/urn-3:HUL.InstRepos:11578059

\section{Terms of Use}

This article was downloaded from Harvard University's DASH repository, and is made available under the terms and conditions applicable to Other Posted Material, as set forth at http:// nrs.harvard.edu/urn-3:HUL.InstRepos:dash.current.terms-of-use\#LAA

\section{Share Your Story}

The Harvard community has made this article openly available.

Please share how this access benefits you. Submit a story.

Accessibility 


\section{SRC-5z \\ The NEW ENGLAND JOURNAL of MEDICINE}

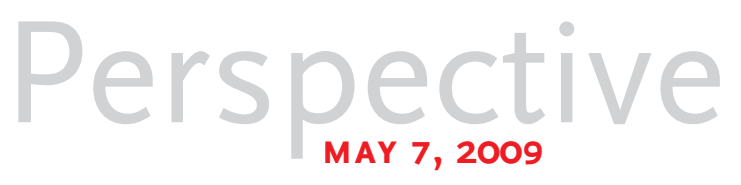

\section{Does Comparative-Effectiveness Research Threaten Personalized Medicine?}

Alan M. Garber, M.D., Ph.D., and Sean R. Tunis, M.D.

T

he American Reinvestment and Recovery Act gives comparative-effectiveness research (CER) a large boost in funding over the next 2 years. Despite a consensus that better information about the

relative effectiveness of different medical interventions is needed to improve the quality and value of care, some view CER with skepticism. Recently, the Partnership to Improve Patient Care, a coalition of 36 industry, patient-advocacy, and clinician organizations, raised concerns that CER will not take adequate account of individual patient differences and may impede the development and adoption of improvements in medical care and "stymie progress in personalized medicine."

The controversy stems in part from a perceived contradiction between the concepts of CER and personalized medicine. In CER, groups of patients are analyzed to compare the effectiveness of al- ternative medical strategies, with the intent of informing clinical decisions and policies affecting health care. The very name "personalized medicine" suggests an approach to care that is based on individuals rather than groups. The term has been used to describe the consideration of characteristics such as age, coexisting conditions, preferences, and beliefs in crafting an individual management strategy; the use of advanced individual genomic information in choosing an expensive biologic agent; and the development of therapies biologically tailored to patient needs, such as customized monoclonal antibodies and vaccines. But far from impeding personalized med- icine, CER offers a way to hasten the discovery of the best approaches to personalization, providing more and better information with which to craft a management strategy for each individual patient.

Perhaps the most prominent examples of modern personalized medicine are genomic tests designed to guide treatment choices (see table). Some are widely recognized as useful, such as testing for human epidermal growth factor receptor type 2 (HER2, also referred to as HER2/neu) to select patients with breast cancer who will benefit from trastuzumab and of testing for the KRAS mutation to determine who is likely to benefit from therapies inhibiting the epidermal growth factor receptor. Genomic medicine, however, has had little impact to date in most areas of care - a fact that some critics blame on payers, claiming that they impose 


\begin{tabular}{|c|c|c|}
\hline \multicolumn{3}{|c|}{ Selected Genomic Biomarkers. } \\
\hline Biomarker & Disease & Drug \\
\hline c-kit & $\begin{array}{c}\text { Gastrointestinal stromal } \\
\text { tumor }\end{array}$ & Imatinib mesylate \\
\hline CCR5 & $\begin{array}{l}\text { Human immunodefi- } \\
\text { ciency virus }\end{array}$ & Maraviroc \\
\hline $\begin{array}{l}\text { Cytochrome P-450 } \\
\text { variants }\end{array}$ & Various disorders & Warfarin, voriconazole \\
\hline EGFR & $\begin{array}{l}\text { Non-small-cell lung } \\
\text { cancer }\end{array}$ & Erlotinib \\
\hline
\end{tabular}

unrealistically high evidence barriers before agreeing to pay for genomic tests. But payers have often championed personalized approaches - for example, by reimbursing for KRAS testing before the Food and Drug Administration (FDA) has fully embraced it. The real bottleneck is often the science itself: progress in identifying clinically important genetic variants has been slow, since seldom does the presence of a common variant greatly increase the relative risk of a serious disease or of severe harm from treatment. Moreover, only some genomic tests provide clinically important information. For example, although the FDA endorsed the use of genomic tests to identify persons with warfarin sensitivity, comparative trials showed that the tests added little value over careful monitoring of the international normalized ratio. ${ }^{2}$ Chromosomal mutation 9p21.3 is associated with increased risk of cardiovascular disease in women, but a recent study showed that knowledge of its presence adds no additional predictive power to the standard information on risk. ${ }^{3}$

The greatest obstacle to the adoption of personalized approaches such as genomic testing, however, is the lack of adequately designed studies assessing their clinical utility. Often there is little consensus about the best way to design and implement such studies. We may know very little about how a test might improve health in typical clinical settings. These are precisely the kinds of issues that CER is designed to address. As the leaders of the $\mathrm{Na}$ tional Heart, Lung, and Blood Institute recently argued, once associations between genotype and drug sensitivity have been identified, studies assessing the clinical benefits of gene-guided management strategies will be needed. ${ }^{4}$ Without knowing how well these strategies work, physicians can't easily apply them or convince patients that a test is worth the out-of-pocket cost. In the case of tests that determine whether a patient is likely to benefit from a cancer-preventive, such as tamoxifen, a misleading result could lead either to unnecessary exposure to side effects or a failure to reduce an elevated risk of cancer. Appropriately designed studies could reveal that a genomic test adds little useful information or, conversely, that the personalized approach works better.

Physicians, recognizing that patients' responses to treatment vary, have long tried to make treatment decisions that are as relevant to the individual patient as possible. In doing so, they have had to balance the findings of formal studies with clinical judgment: without the guidance of well-designed studies, physicians' hunches about the effectiveness of treatments are frequently wrong, but the right kinds of studies have not always been available. There may be no high-quality studies of a treatment, or the patient or the treatment being considered may differ in important ways from those already studied.

For many years, clinical epidemiology and related fields have sought to improve our understanding of treatment effects at the individual level by analyzing subgroup effects and developing clinical prediction rules. Yet with too few appropriately designed studies, physicians, patients, and families have often had little guidance about which patients were most likely to benefit from a clinical strategy. Perhaps the most important goal of CER is to broaden and deepen such information, providing tools for matching medical care much more precisely to individual patients.

Although CER's methods are not entirely new, the federal initiative will support research that is both more comprehensive encompassing many more treatments and conditions, as well as more complete outcome measures - and more relevant to real-world clinical decisions than traditional clinical research. For example, large observational databases and pooled trial results can be used to learn more about the subgroups of patients who benefit from therapy. A recent study showed that mortality was similar overall for patients with coronary disease whether treated with percutaneous coronary intervention (PCI) or coronary-artery bypass surgery. However, the results varied strikingly with age: mortality was much lower with surgery among patients 65 years of age or older and lower with PCI among those 55 years of age or younger. 5 Such information is important not only for pa- 
tients with varying risk characteristics and coexisting conditions but for women, members of minority groups, and others who have historically been underrepresented in clinical trials. Current CER efforts aim to ensure that much more useful data will be collected and that better methods will be developed for understanding differences in effectiveness among different patient groups.

As CER guides individual patient care, it will also guide and promote innovation. In some cases, federal support of the research will reduce the development costs of new medical technologies. Emerging CER methods promise to be more rapid, relevant, and efficient. Furthermore, the development of explicit standards for CER methodology will help to clarify which forms of evidence are sufficiently informative for health care decision makers an advance that will be particularly important for the most novel personalized approaches, such as the creation of monoclonal antibodies directed against a cancer in a specific patient. Such exciting prospects do not obviate the need for evaluation; they change the kind of evaluation that is needed. CER may well re- quire innovative approaches to clinical trials - such as adaptive, pragmatic, or other novel trial designs. Individualized therapies might be evaluated through the random assignment of patients to tailored therapy or a conventional alternative; such an approach would neither disadvantage the personalized therapy nor presume its superiority.

The deepest concern about CER is that it will be misused, which is why some legislators seek to prohibit information on comparative effectiveness from influencing coverage policy and payment decisions. But surely these decisions will not be improved by discouraging the use of the most relevant and valid information about what works and in whom. CER is not a panacea, but it is a key to individualized care and innovation, not a threat. An initiative to advance our knowledge about the effectiveness of clinical strategies can hasten the day when personalized medicine transforms health care.

Dr. Garber and Dr. Tunis report serving on the Institute of Medicine (IOM) Committee on Priorities for Comparative Effectiveness Research. Dr. Garber reports receiving lecture fees from De Novo Ventures, Express Scripts, and Covidien and consulting fees from McKinsey and Co. and Perlegen, a genomics company. Dr. Tunis also reports serving as director of the Center for Medi- cal Technology Policy, which receives unrestricted funding from a number of foundations, government grants, as well as health plans and life sciences companies. No other potential conflict of interest relevant to this article was reported.

The views expressed in this article are those of the authors and do not necessarily represent those of the IOM, the IOM Committee on Priorities for Comparative Effectiveness Research, the Department of Veterans Affairs, or Stanford University.

Dr. Garber is a staff physician at the Veterans Affairs Palo Alto Health Care System in Palo Alto, CA, and a professor of medicine, director of the Center for Primary Care and Outcomes Research, and director of the Center for Health Policy at Stanford University, Stanford, CA. Dr. Tunis is the founder and director of the Center for Medical Technology Policy, Baltimore.

1. Partnership to Improve Patient Care. Individualized patients, personalized care. Washington, DC: PIPC, 2009. (Accessed April 17, 2009, at www.improvepatientcare.org/ individualized-patients-personalized-care.)

2. Anderson JL, Horne BD, Stevens SM, et al. Randomized trial of genotype-guided versus standard warfarin dosing in patients initiating oral anticoagulation. Circulation 2007; 116:2563-70.

3. Paynter NP, Chasman DI, Buring JE, Shiffman D, Cook NR, Ridker PM. Cardiovascular disease risk prediction with and without knowledge of genetic variation at chromosome 9p21.3. Ann Intern Med 2009;150:65-72.

4. Shurin SB, Nabel EG. Pharmacogenomics — ready for prime time? N EnglJ Med 2008; 358:1061-3.

5. Hlatky MA, Boothroyd DB, Bravata DM, et al. Coronary artery bypass surgery compared with percutaneous coronary interventions for multivessel disease: a collaborative analysis of individual patient data from ten randomised trials. Lancet 2009;373:1190-7.

Copyright (c) 2009 Massachusetts Medical Society.

\title{
Debate about Funding Comparative-Effectiveness Research
}

\author{
Jerry Avorn, M.D.
}

he proposal to include $\$ 1.1$
billion for comparative-effec-
tiveness research (CER) in the fed-
eral stimulus package encountered
a vigorous and well-coordinated
backlash. The campaign to gut
this funding ultimately failed, but
the debate it engendered and the
resonance of the opposition's ar-
guments in both lay and policy circles reveal much about the issues that will surround such research and its application in the coming years.

The contested provisions were designed to support studies comparing the efficacy and safety (and, by extension, the cost-effectiveness) of alternative ways of addressing common clinical prob- lems. Interventions to be evaluated will include pharmaceuticals, devices, procedures, and diagnostic approaches, such as imaging studies. This research will fill important information gaps facing clinicians, patients, and payers concerning what works best. Currently, the Food and Drug Administration (FDA) often approves new 